\title{
Development of Intelligent Wind Turbine Unit with Tandem Wind Rotors and Double Rotational Armatures (2nd Report, Characteristics of tandem wind rotors)
}

\author{
Koichi KUBO $^{* *}$ and Toshiaki KANEMOTO** \\ ${ }^{* *}$ Graduate School of Engineering, Kyushu Institute of Technology \\ Sensui 1-1, Tobata, Kitakyushu, Fukuoka, 804-8550, Japan \\ E-mail: g344122k@tobata.isc.kyutech.ac.jp
}

\begin{abstract}
The authors have invented the superior wind turbine unit which is composed of the tandem wind rotors and the double rotational armature type generator without the traditional stator. The large-sized front wind rotor and the small-sized rear wind rotor drive the inner and the outer armatures respectively, in keeping the rotational torque counter-balanced. Such operating conditions may be able to make the output higher than the traditional wind turbines, and to keep the output constant in the rated operation mode without the brakes and/or the pitch control mechanism. The unique rotational conditions of the tandem wind rotors and the fundamental characteristics of this unit were presented at the previous paper. Continuously, this paper discusses experimentally the effects of the tandem wind rotor profiles on the characteristics of this unit. The desirable profiles and the main results are as follows. (1)The optimum diameter ratio is $D_{R F}$ (rear wind rotor diameter divided by the front wind rotor diameter) $=0.84$, and the axial distance between both wind rotors should be set as short as possible. (2)The output is higher while the relative tip speed ratio increases as compared with the single wind rotor.
\end{abstract}

Key words: Wind Turbine, Wind Energy, Blade, Tandem Wind Rotors, Generator

\section{Introduction}

Wind is clean, renewable and homegrown energy source of the electric power generation, and has been positively/effectively utilized to cope with the warming global environment. The traditional wind turbines, however, may have some weak points as follows. The large-sized wind turbines generate the high output at the moderate wind velocity, but it is not operated at the weak wind in general. The small-sized wind turbines are suitable for the weak wind, but the output is smaller. That is, the size of the wind rotor must be correctly/appropriately selected in conformity with the wind circumstances. Moreover, the blade of the wind rotor must be equipped with the brakes and/or the pitch control mechanisms, in general, to suppress the abnormal rotation and generated overload at the strong wind, and to keep the good quality of the electric power supply. To overcome these weak points, the authors have invented the superior wind turbine unit ${ }^{(1)}$, as shown in Fig. 1. This unit is composed of the large-sized wind rotor, the small sized-wind rotor and the peculiar generator with the inner and the outer armatures without the traditional stator. The front and the rear wind rotors for the upwind type drive the inner and the outer armature, respectively. The rotational speeds and the directions of both 
wind rotors/armatures are free, and automatically adjusted pretty well in response to the wind circumstances. Then, this unit is called "Intelligent Wind Turbine Unit" by the authors. The idea of the tandem wind rotors has been proposed before. Kowintec Co. Ltd. has succeeded only to increase the output of the wind turbine using the prototype tandem wind rotors with the gearbox ${ }^{(2)}$. Professor I. Ushiyama could also increase the output using the model tandem wind rotors ${ }^{(3)}$. On the contrary, the operation of the proposed tandem wind rotors is in cooperation with the double rotational armature type generator without the gearbox, and the pitch control mechanism.

The superior characteristics of this unit was verified preliminarily ${ }^{(1)}$, and the double rotational armature type doubly fed induction generator was prepared for supplying this unit to the power grid system ${ }^{(4)}$. Continuously, this paper discussed the effect of the wind rotor profiles on the turbine characteristics accompanied with the flow conditions around the wind rotors.

\section{Superior Operation of Tandem Wind Rotors}

The operation of the tandem wind rotors is in cooperation with the double rotational armature type generator, as described above. Then, the rotational directions and the speeds of the tandem wind rotors/armatures are automatically adjusted in response to the wind velocity, as shown in Fig. 2, where such operations ${ }^{(1)}$ are explained briefly again for helping the discussions of the experimental results. Both wind rotors start to rotate at the low wind velocity, namely the cut-in wind velocity, but the rear wind rotor counter-rotates against the front wind rotor. The rear wind rotor reaches the maximum rotational speed at the rated wind velocity. With more increase of the wind velocity, the rotational speed of the rear wind rotor decreases gradually, stops and begins to rotate in the same direction as the front wind rotor, so as to coincide with the rotational torques of the front wind rotor. The reason of such behaviors is that the small-sized wind rotor must work in the blowing mode against the attacking wind, because the rear wind rotor in the turbine mode cannot generate the same rotational torque as the large-sized front wind rotor.

The following discussions are, as described before, to get the desirable profiles as the tandem wind rotors and to know the effects of the blade profiles on the wind rotor characteristics, as the first step to optimize the specifications of the tandem wind rotors playing the above behaviors.

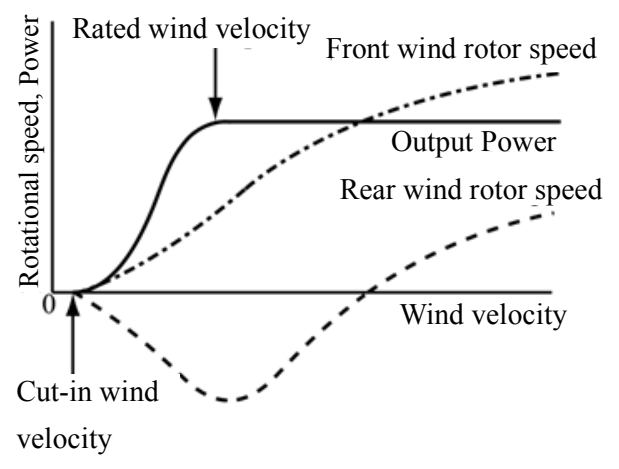

Fig.2 Operation of the intelligent wind turbine unit

\section{Model Wind Rotors and Experiments}

The diameter of the front wind rotor is $d_{F}=500 \mathrm{~mm}$, and the rear wind rotor diameter can be changed from $d_{R}=260 \mathrm{~mm}$ to $560 \mathrm{~mm}$, for the experiments in the wind tunnel. The axial distance between the front and the rear wind rotor (the twist center of the blade) can be also 
changed from $l=40 \mathrm{~mm}$ to $200 \mathrm{~mm}$, to know the desirable dimensions. The blade profiles of the front and the rear wind rotors are shown in Fig. 3, where the front and the rear blade setting angles $\beta_{F}, \beta_{R}$ measured from the tangential direction at the blade tip given in Fig. 4 can also be changed. The blade $\mathrm{E}$ is supplied to the front and/or the rear wind rotors, and has no camber without the twist. The front blade $\mathrm{G}$ is formed with MEL002 aerofoil ${ }^{(5)}$ and has the twist to get the desirable angle of attack $\alpha=7$ degrees, as the single wind rotor with the blade tip speed ratio $\lambda=6$ [= (blade tip speed) / (wind velocity).$\quad$ The front and the rear blade numbers are $Z_{F}=3, Z_{R}$ $=5$ which are optimized in the previous paper ${ }^{(1)}$. Hereafter, the tandem wind rotors are called "Tandem wind Rotor EE" which is composed of the front blade E and the rear blade E, "Tandem Wind Rotor GE" which is composed of the front blade $G$ and the rear blade E, "Tandem Wind Rotor GG" which is composed of the front blade $\mathrm{G}$ and the rear blade G, and "Single Wind Rotor G" with the front wind rotor $\mathrm{G}$.

The model wind rotors were set perpendicular to the wind direction, at the outlet of the wind tunnel with the nozzle diameter of $800 \mathrm{~mm}$, as shown in Fig. 5. The front and the rear wind rotors were connected directly and respectively to the isolated motor with the inverter, in place of the peculiar generator. The rotational torques of the front and the rear wind rotors were counter-balanced by the rotational speed control. The turbine characteristics in the following discussions are evaluated without the mechanical losses of the bearings and the pulley system. The flow conditions at the wind tunnel outlet are almost uniform and axis-symmetry without the swirl, within the nozzle diameter. The Reynolds number based on the relative velocity and the chord length at the blade tip is $R e=5.8 \times 10^{4}-1.4 \times 10^{5}$. The fundamental information for the target of this paper can be got though $R e$ number is far from the large-sized prototype, because $R e$ number is close to the turbulent condition and the comparatively large turbulent

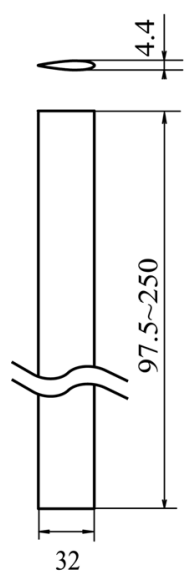

Front and/or Rear Blade E

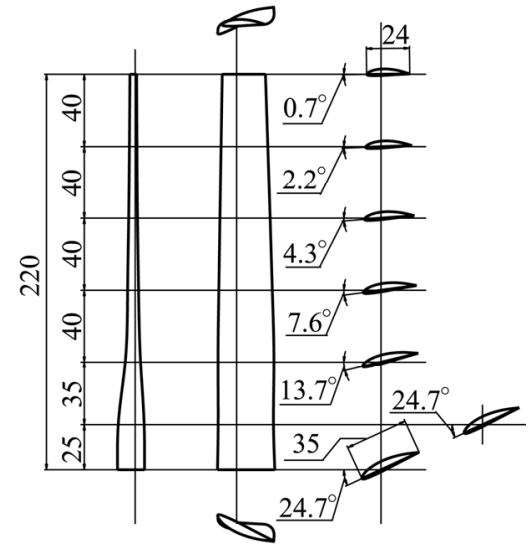

Front blade $\mathrm{G}$

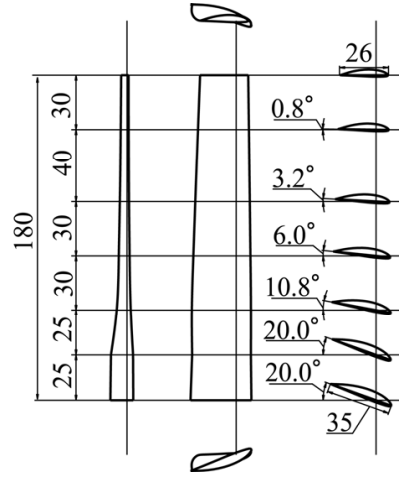

Rear blade $\mathrm{G}$

Fig.3 Blade profiles

Unit: mm

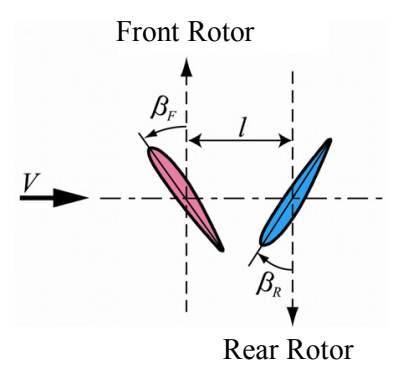

Fig.4 Blade setting angles

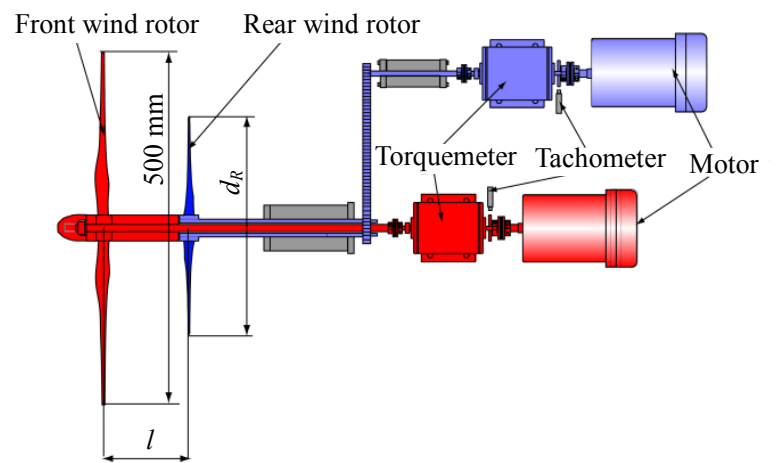

Fig. 5 Test stand for model tandem wind rotors 
fluctuation probably makes the flow along the blade turbulent condition. The similarity law for the wind velocity, the rotational speed and the wind rotor dimensions will be discussed at the next paper.

\section{Desirable Profiles as Tandem Wind Rotors}

\subsection{Diameter ratio of front and rear wind rotors}

To know the desirable diameter ratio $D_{R F}\left[=d_{R} / d_{F}\right]$, the characteristics of the tandem wind rotors were investigated by changing the diameter of the rear wind rotor, as shown in Fig. 6. The output coefficient is defined with $C_{P}=P /\left(\rho A V^{3} / 2\right)$ and the maximum output coefficient at each $D_{R F}$ is denoted by $C_{P \max }$, where $P$ is the output, $A$ is the area of the front wind rotor, $\rho$ is the ambient air density, $V$ is the wind velocity, $N$ is the rotational speed [subscript $F, R, T$ : the front, the rear and the relative rotational speeds, $N_{T}=N_{F}-N_{R}$, (the rotational direction of $N_{F}$ is positive), subscript opt means the rotational speed giving $\left.C_{P \max }\right]$, and $L$ is the dimensionless axial distance between both wind rotors $\left[=l / d_{F}, l\right.$ : the axial distance as shown in Fig. 5]. Besides, $\beta_{F}$ and $\beta_{R}$ of these wind rotors are the optimum setting angles as presented in the next chapter. With the increase of the rear rotor diameter, that is $D_{R F}$ becomes larger, the rotational speed of the front wind rotor $N_{\text {Fopt }}$ becomes slower with almost the same speed regardless of the blade profiles. The front blade profiles, however, affects markedly the rotational speed of the rear wind rotor $N_{\text {Ropt }}$, with the decrease of $D_{R F}$. The front blade G with the reasonable twist makes $N_{\text {Ropt }}$ comparatively faster at the smaller $D_{R F}$ (see Tandem Wind Rotor $\mathrm{GE}$ ), in comparison with the front blade $\mathrm{E}$ without the twist. That may be caused from the difference of the flow condition at the rear wind rotor inlet, namely, the front wind rotor outlet. That is, the two dimensional front blade E has unacceptable flow separation whose scale is large at the smaller radius due to the poor and

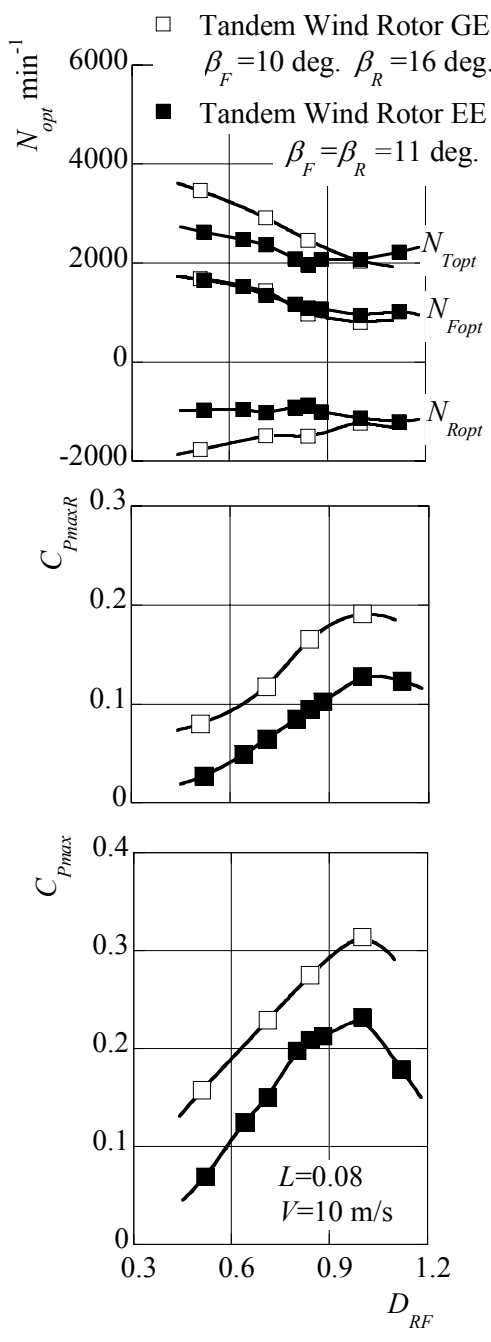

Fig.6 Effect of the diameter ratio on the output characteristics

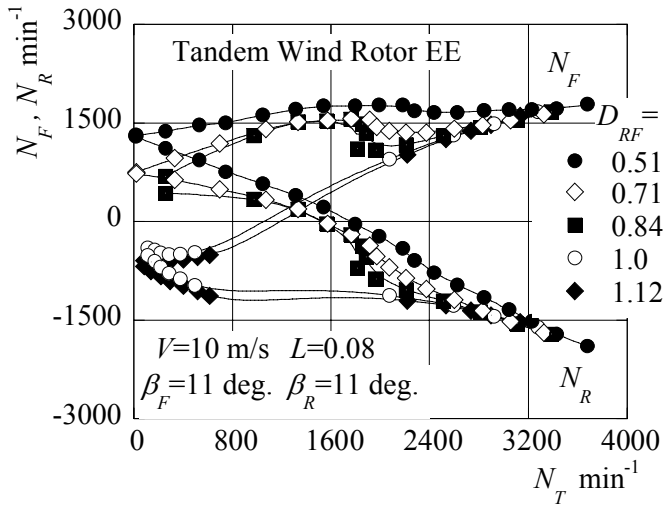

(a) Tandem Wind Rotor EE

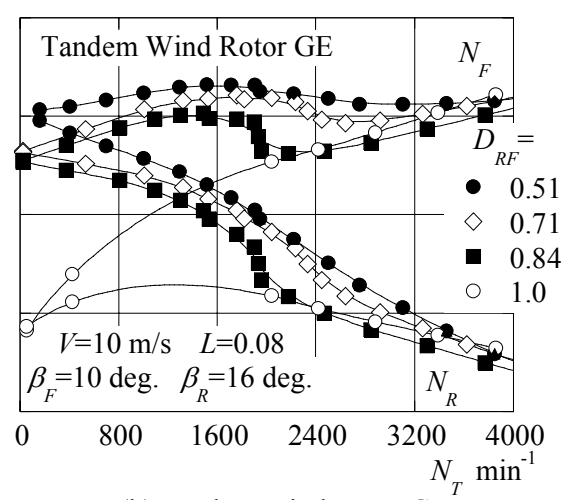

(b) Tandem Wind Rotor GE

Fig.7 Rotational behaviors of the tandem wind rotors 
negative angle of attack, and the separation deteriorates the rear wind rotor rotation. Such rotational speeds resultantly contribute the relative rotational speed $N_{\text {Topt }}$.

The maximum output $C_{P \max }$ is larger with increment of $D_{R F}$ and has the maximum value at $D_{R F}$ is about 1.0, and $C_{P \max }$ of Tandem Wind Rotor GE composed of the twisted blades is higher than that of Tandem Wind Rotor EE. As recognized in Fig. 6, the maximum output coefficient $C_{P \max }$ is affected mainly by the maximum output coefficient of the rear wind rotor output $C_{P \max R}$.

Figure 7 shows the rotational behaviors of the tandem wind rotors. The rotational behaviors of the front and the rear wind rotors is changed drastically at $D_{R F}=0.84$, in the smaller $N_{T}$. That is, the rear wind rotor rotates in the same direction as the front wind rotor, while $D_{R F}$ is less than 0.84. On the contrary, the front wind rotor rotates unfortunately at the same direction as the rear wind rotor, while $D_{R F}$ is more than 0.84 . This rotational behavior of the front wind rotor is not acceptable as for the proposed intelligent wind turbine unit because the front wind rotor must keep the rotational direction as expected in Chapter 2 (see Fig. 2).

The features of the maximum output coefficient and the rotational behaviors against $D_{R F}$ are independent to the front blade profiles, as recognized in Figs. 6 and 7. Therefore, the desirable diameter ratio getting the sufficient output and playing the expected rotational behavior is close to $D_{R F}=0.84$.

\subsection{Axial distance between front and rear wind rotors}

Figure 8 shows the effect of the axial distance between the front and the rear wind rotor twist centers on the turbine characteristics, in keeping the desirable diameter ratio, where $D_{R F}$ of Tandem Wind Rotor GE is 0.84 and $D_{R F}$ of Tandem Wind Rotor EE is 0.71 . The rotational speed of the front wind rotor $N_{\text {Fopt }}$ becomes slower with the decrease of $L$ because of the flow interaction between both wind rotors, irrespective of the blade profile. Then, the rotational speed of the front wind rotor with blade $G$ is slightly slower than that of the front blade E, but the front blade $\mathrm{G}$ makes the rear wind rotor speed faster. Resultantly, the relative rotational speed $N_{\text {Topt }}$ of Tandem Wind Rotor GE is slightly faster than that of Tandem Wind Rotor EE. Such characteristics are scarcely affected by the diameter ratio $D_{R F}$.

The maximum output coefficient $C_{P \max }$ is higher at the smaller $L$ because the rear wind rotor can get effectively the wind energy as discussed after. Besides, $C_{P \max }$ of Tandem Wind Rotor GE is markedly higher than that of Tandem Wind Rotor EE because not only $C_{P \max }$ at $D_{R F}=0.84$ of the former is higher than one at $D_{R F}=0.71$ of the latter but also the rotational torque of the former composed of the reasonable blades is larger than one of the latter.

These data suggest that the rear wind rotor should be set as close as possible to the front wind rotor, but taking the bending moment and vibration of the blade into account.

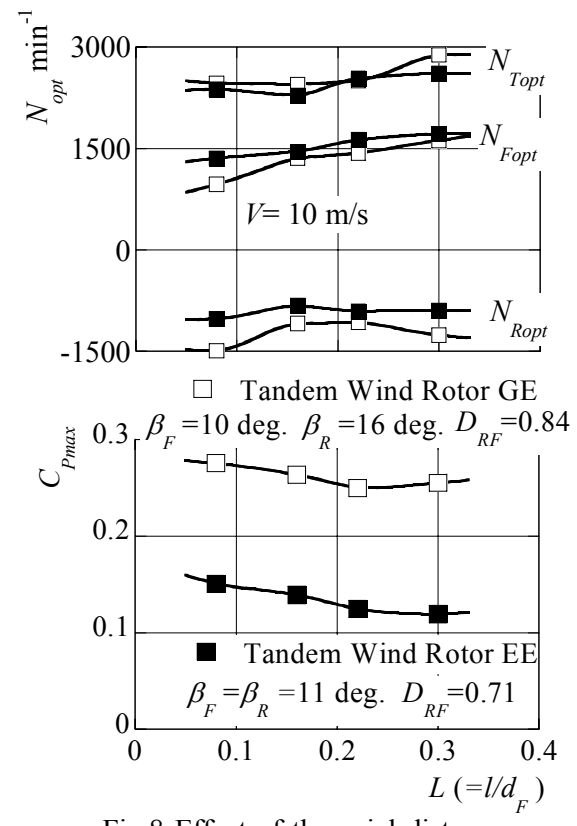

Fig. 8 Effect of the axial distance on the output characteristics
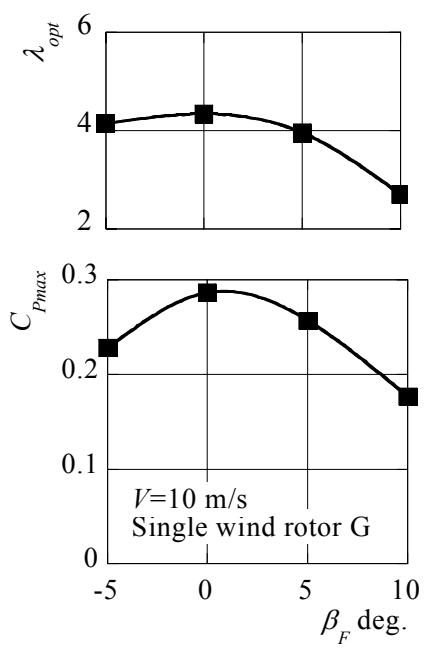

Fig.9 Output of the single wind rotor 


\section{Characteristics of Tandem Wind Rotors}

\subsection{Effect of blade setting angles on characteristics}

Prior to evaluations of the tandem wind rotors, the characteristics of the front blade $\mathrm{G}$ as the single wind rotor "Single Wind Rotor G" were investigated. Figure 9 shows the maximum output coefficient $C_{P \max }$ at each blade setting angle $\beta_{F}$ and the tip speed ratio $\lambda_{\text {opt }}$ giving $C_{P \max }$. The maximum output coefficient is obtained at $\beta_{F}=0$ degree which is just expected in the blade design. Besides, $\lambda_{\text {opt }}$ also shows the maximum at this angle, but the value is about 4.3 corresponding to the $\alpha=8.8$ - 13.6 degrees, which are estimated from the axial velocity $0.667 \mathrm{~V}$ in the axial-symmetric ideal flow conditions and near the maximum lift point of MEL002 aerofoil $^{(5)}$

The effects of the front and the rear blade setting angles $\beta_{F}$ and $\beta_{R}$ on the wind rotor characteristics are shown in Fig. 10, where $\lambda_{\text {Fopt }}, \lambda_{\text {Ropt }}, \lambda_{\text {Topt }}$ is the front, the rear and the relative tip speed $\left[\lambda_{T}=\right.$ (relative tip speed) / (wind velocity)] ratios giving $C_{P \max }$. The maximum output coefficient $C_{P \max }$ can be obtained at the front and the rear blade setting angles $\beta_{F}=10$ degrees and $\beta_{R}=16$ degrees, in the presented setting angles. The lowest $C_{P \max }$ is at $\beta_{F}=0$ degree irrespective of $\beta_{R}$, because the wind energy may not be supplied sufficiently to the rear wind rotor as recognized by $\lambda_{\text {Ropt }}$.

Above results mean that the optimum blade setting angles of the front blade as the tandem wind rotors differs from $\beta_{F}=0$ degree as the single wind rotor, as for the front blade $\mathrm{G}$. Moreover, it is necessary to modify the profile of the rear blade $\mathrm{E}$, as the maximum value of $C_{P \max }$ is unacceptable as compared with Single Wind Rotor G shown in Fig. 9.

The tip speed ratios of the front wind rotor $\lambda_{\text {Fopt }}$ are scarcely affected by the rear blade setting angle $\beta_{R}$, and depend on the front blade setting angle $\beta_{F}$. On the contrary, the tip speed ratios of the rear wind rotor $\lambda_{\text {Ropt }}$ are affected by not only $\beta_{R}$ but also $\beta_{F}$, and $\lambda_{\text {Ropt }}$ decreases, that is the absolute rotational speed increases, with the increase of the front blade

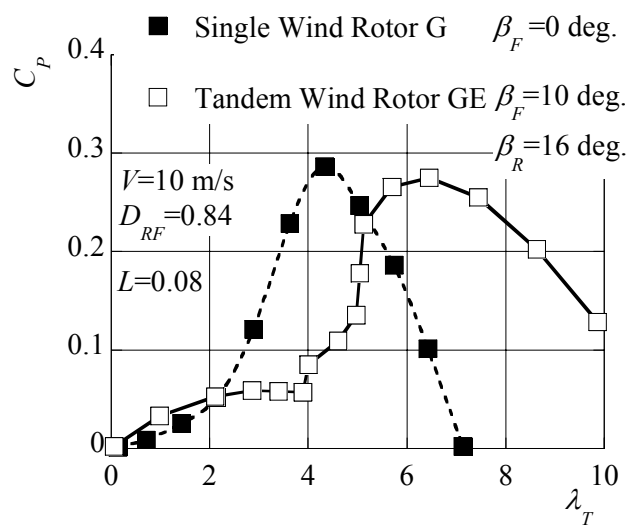

Fig.11 Output characteristics of Tandem Wind Rotor GE.
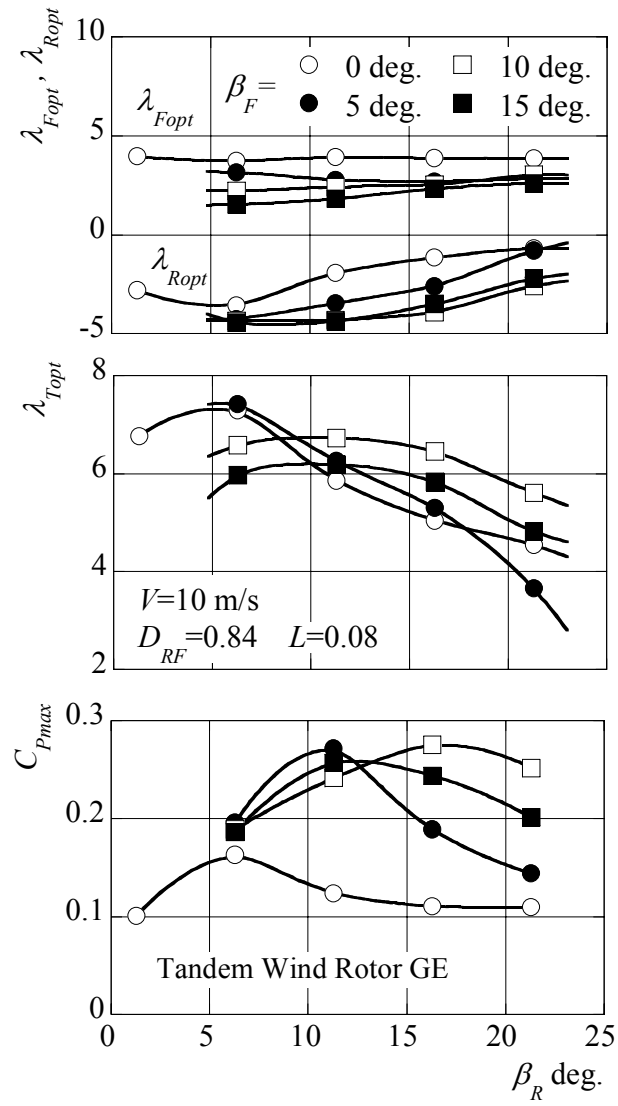

Fig.10 Effects of blade setting angles on the output characteristics.

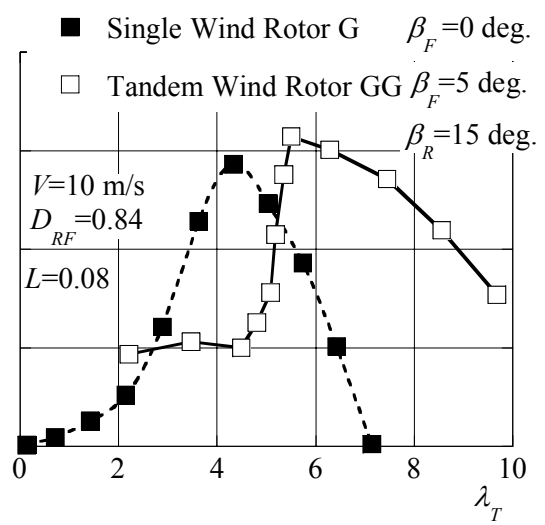

Fig.12 Output characteristics of Tandem Wind Rotor GG. 
setting angle $\beta_{F}$. Such the front and the rear tip speed ratios justly determine the relative tip speed ratio $\lambda_{\text {Fopt }}$.

\subsection{Effect of tip speed ratio on the outputs}

Figure 11 shows the output coefficient $C_{P}$ against the relative tip speed ratio $\lambda_{T}$, in comparison with $C_{P}$ of Single Wind Rotor G. The relative tip speed ratio $\lambda_{\text {Topt }}$ giving the maximum output of Tandem Wind Rotor GE is faster than that of Single Wind Rotor G, but the output coefficient of Tandem Wind Rotor GE is unacceptable. The latter is caused by the rear wind rotor without the twist. Then, the rear baled $\mathrm{E}$ was modified to the blade $\mathrm{G}$ as shown in Fig. 3, where the blade was designed so as to get the desirable angle of attack ( $\alpha=11 \mathrm{deg}$.) irrespective of the radial position in consideration with the flow conditions given in Fig. 14. The maximum output coefficient can be improved successfully but the relative tip speed ratio $\lambda_{T}$ may be unacceptable as shown in Fig. 12, where the desirable blade setting angles of Tandem Wind Rotor GG are $\beta_{F}$ $=5 \mathrm{deg}$. $\beta_{R}=15$ degrees because these value are different from designing blade setting angles of Blade $\mathrm{G}$

\section{Flow Conditions around Wind Rotors}

The flow around the wind rotors were measured in the steady state conditions, using the 5 holes Pitot tube, where the measurement sections are shown in Fig. 13. Figure 14 show the flow conditions around the single wind rotor with the front blade $G$ at the maximum output operation, where $R$ is the dimensionless radius $\left[=2 r / d_{F}\right], V_{M t m}, V_{\Theta t m}$ and $V_{R t m}$ are the axial, the swirling (positive in the direction of front wind rotor rotation), the radial (positive in the outward direction) velocity components divided by the inlet wind velocity $V$ at $\mathrm{M} 0$, and the angle of attack $\alpha$ is estimated with the flow conditions at the section M1 and the blade setting angle at each radius position. The flow runs outward even in the inlet section M1, due to the blockage effect of the wind rotor, and the axial velocity $V_{M t m}$ decreases more or less. The outward flow $V_{R t m}$ is promoted in the wind rotor, and the axial velocity decrease more at the section M2 with the increase of the radial flow, especially in the blade tip side. As such outward flows decrease the axial flow

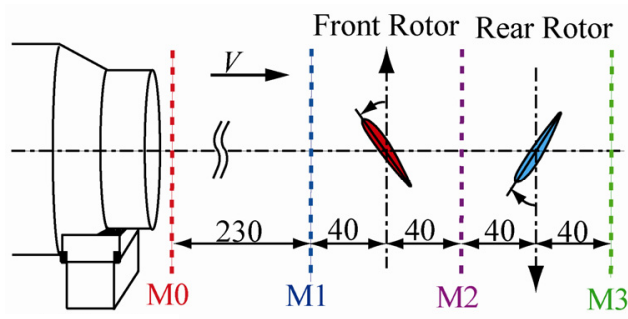

Fig.13 Positions of the measurement sections.
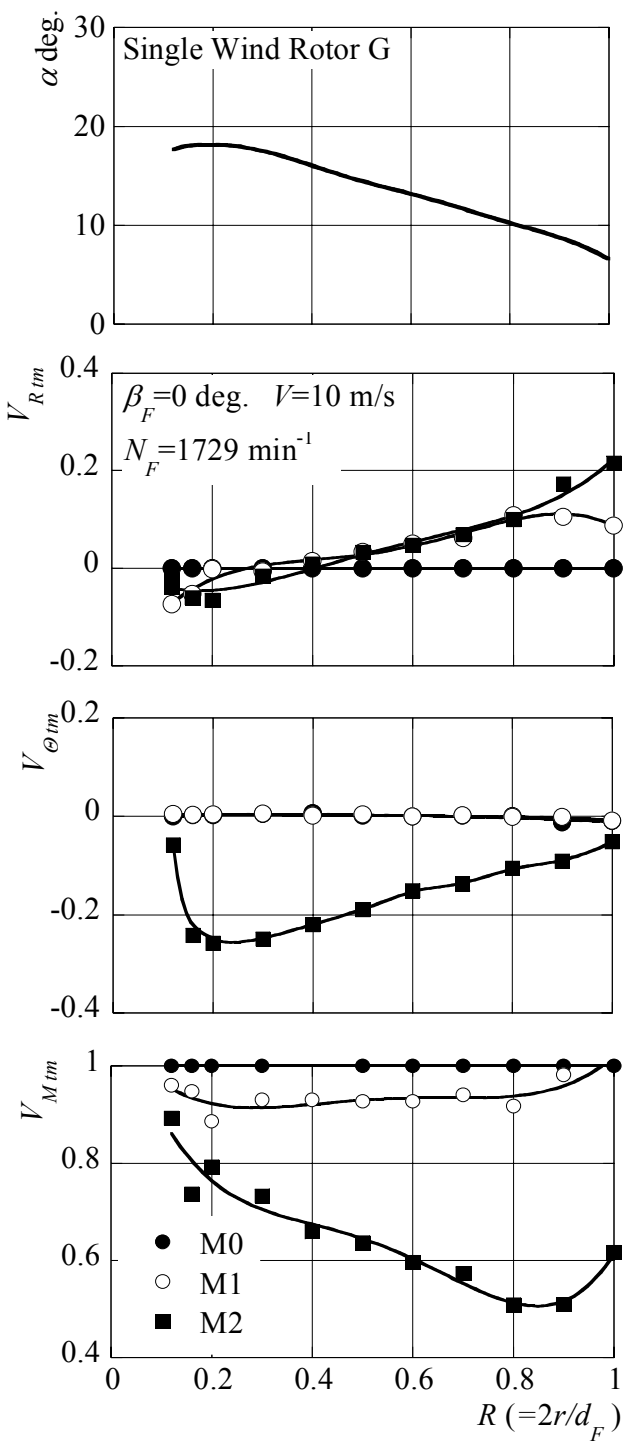

Fig.14 Flow conditions around the single wind rotor. 
velocity downstream of the front wind rotor, the rear wind rotor set in the some distance from the front wind rotor cannot get the sufficient wind energy. The angle of attack $\alpha$ is reasonable without the stall judging from the performance data of MEL002 aerofoil ${ }^{(5)}$ though the angle changes from 7 degrees to 18 degrees in the radial direction, and the rotor generates the swirling velocity component having nearly the free vortex pattern.

Figure 15 shows the flow conditions around Tandem Wind Rotor GG at the maximum output operation. The outward flow is almost the same as that of Single Wind Rotor G, because the rear wind rotor profile is reasonable. The axial velocity $V_{M t m}$ distribution, however, quiet differs from one of Single Wind Rotor $\mathrm{G}$ with $\beta_{F}=0$ degree, though the absolute value cannot be compared due to the difference of the rotational speeds. This axial velocity distribution at the section M2 is controlled by the front blade setting angles, and the distribution where the blade setting angle is changed to $\beta_{F}=0$ degree, which is denoted with the dash line in Fig. 15, is similar to the distribution shown in Fig. 14.

The angle of attack $\alpha$ to the front blade is slightly larger than $\alpha$ shown in Fig. 14, but the angle scarcely occur the large separation on the front blade ${ }^{(5)}$. Besides, the angle of attack for the rear blade, which is estimated at the section M2, is also reasonable. Then, the output can be improved with the higher relative rotational speed (see Fig. 11 and 12), though the angular momentum change through the front or the rear wind rotors is somewhat small as compared with Single Wind Rotor $\mathrm{G}$ (see $V_{\Theta t m}$ in Figs. 14 and 15).

\section{Concluding Remarks}

The characteristics and the flow conditions of the preliminary model tandem wind rotors were investigated experimentally, as the first step to optimize the specifications of Intelligent Wind Turbine Unit. The desirable profiles as the tandem wind rotors are that the diameter ratio is $D_{R F}=$ (rear wind rotor) / (frond wind rotor) $=0.84$ and the axial distance between both wind rotors should be set as short as possible. Besides, the output of the reasonable tandem wind rotors is higher while the relative tip speed ratio increases as compared with the single wind rotor.

The optimum specifications of the tandem wind rotors will be presented at the next paper.

\section{Acknowledgements}

The authors wish to thank to Messrs K. Ikeda, H. Mitarai and T. Nishikawa graduated from Kyushu Institute of Technology, Mr. A.M Galal of graduate school of Kyushu Institute of technology
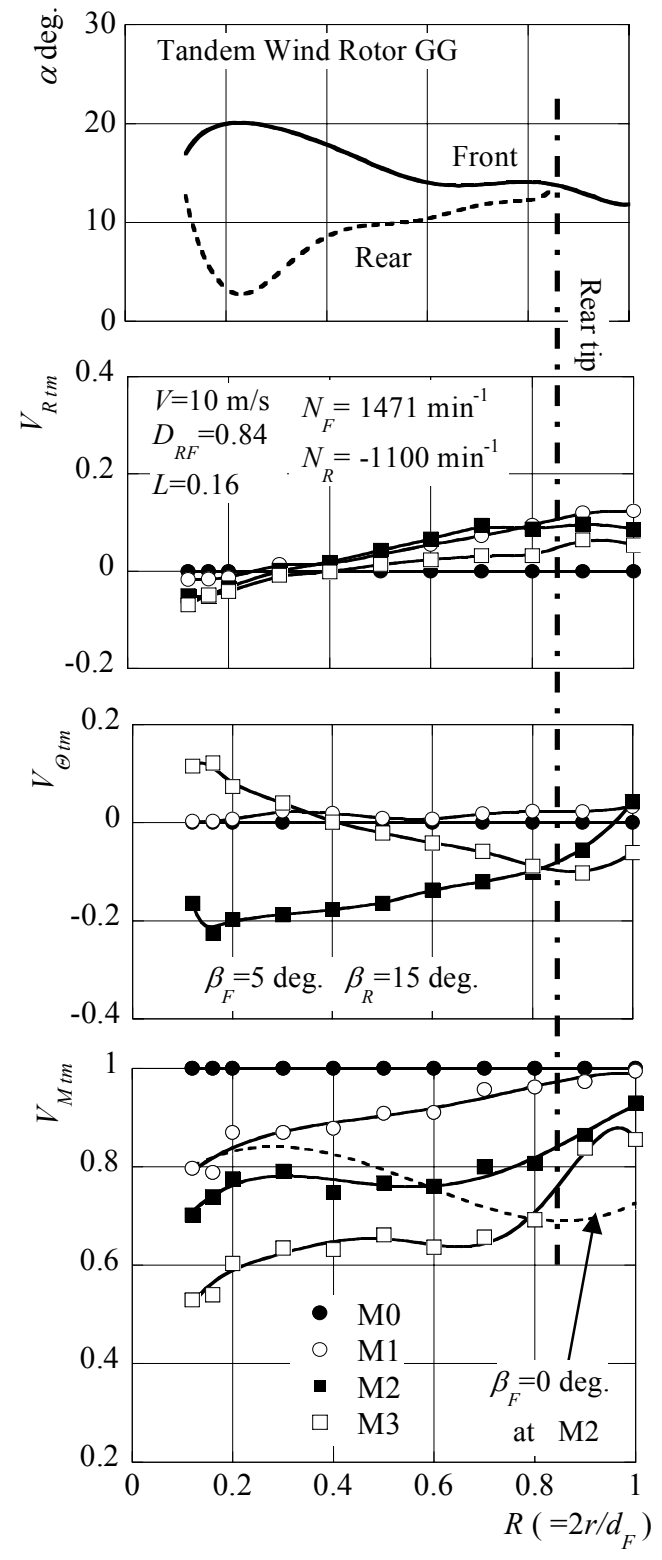

Fig.15 Flow conditions around Tandem Wind Rotor GG. 
and Mr. Y. Hano of Kyushu Institute of Technology for helpful in doing experiment and discussed about this paper. Some parts of this fundamental research were co-sponsored by JFE 21st Century Foundation and Research Project: Grant-in-aid for Scientific Research (c) (2) in Japan and Japan Science and Technology Agency, Fukuoka Industry Science \& Technology Foundation and Japan Science and Technology Agency.

\section{References}

(1)Kanemoto, T. and Ahmed Mohamed Galal, Development of Intelligent Wind Turbine Generator with Tandem Wind Rotors and Double Rotational Armatures, JSME International Journal, Ser. B, Vol. 49, No. 2(2006), pp.450-457.

(2)http://www.kowintec.com/English/intro/info.htm

(3)Ushiyama, I. et al (1996). "An Experimental Study of the Two Staged Wind Turbines," Proceedings of World Renewable Energy Conference, pp. 909-912.

(4)Toshiaki Kanemoto, Ahmed Mohamed Galal, Kota Ikeda, Hiromi Mitarai, and Koichi Kubo, Intelligent Wind Turbine Generator with Tandem Rotors Applicable to Offshore Wind Farm (Characteristics of Peculiar Generator, and Performance of Three Dimensional Blades), Proceedings of the 17th International Offshore and Polar Engineering Conference, Lisbon, Portugal, (2007), pp.363-368.

(5) http://riodb.ibase.aist.go.jp/db060/index.html 